\title{
Proactive Maintenance as a Tool of Optimization for Vehicle Fleets, in Terms of Economic and Technical Benefits
}

\section{Lubomír Ambriško ${ }^{1}$ and Katarína Teplická ${ }^{2}$}

Institutes of ${ }^{1}$ Logistics and Transport and ${ }^{2}$ Earth Resources

Technical University of Košice, Faculty of Mining, Ecology, Process Control and Geotechnologies, Letná 1/9, 04200 Košice, Slovakia

lubomir.ambrisko@tuke.sk, katarina.teplicka@tuke.sk

Abstract: Maintenance is one of the more important processes that affect productivity and creates added value, for the main process within every company. The aim of this paper is to highlight the process of vehicle fleet maintenance and the evaluate the economic and technical benefits, in terms of optimizing the maintenance process. We used economic, comparative analysis to evaluate the maintenance process. Pareto analysis on the principle (80/20\%) presents critical service activities for each type of bus. Critical services of the maintenance process are shock absorbers, cooler, planning service, brake lines. Important features of the maintenance process are cost optimization, capacity planning, workload utilization, optimal material delivery and monitoring the fulfillment of the plan for every company, in various areas of industry. The solution to the problems of fleet maintenance is the introduction of a proactive maintenance approach, aimed at improving the individual activities and capabilities of the vehicles used in the process.

Keywords: maintenance; efficiency; plan; life cycle; vehicle fleet

\section{Introduction}

Since early 2000, proactive maintenance in Europe, and prognostic and health management in the US have been developed to go beyond classical maintenance strategies. Both use the monitoring parameters, which allow the failure prevision of machines [1]. Preventive maintenance is planned and is performed before the machines fail [2] e. g. it prevents the machines from closing due to the degrading [3] (deterioration, such as wear, fatigue, and corrosion are common [4]). The aim of proactive maintenance is using historical data, empirical tests and statistical calculations to avoid machine breakdowns [5]. Urban buses require different levels of preventive maintenance. The higher level of the preventive maintenance, the more maintenance cost will arise [6]. 
Buses, in bus transportation companies, are maintained regularly in a fixed time or mileage intervals in maintenance depots [7]. The important component in the bus transit operations planning process is the scheduling of maintenance activities [8]. In work [9] was compared the operational efficiency of the urban buses in various stages of their operational life. Work [10] deals with the implementation of the prescribed maintenance of buses and the maintenance costs were analyzed by Pareto. Maintenance has changed from corrective to preventive to predictive and proactive [11].

Proactive maintenance is a key instrument for the vehicle fleet of bus transport. Her significance is in economic, technical, social, environmental benefits. Industry 4.0 concept or in integrating the smart system in transport is also an important step around the sustainability of bus transport in every state. High costs and high energy consumption are factors for changes in the vehicle fleet of bus transport areas. Rajput et.al said Industry 4.0 is progressing exponentially and offers a productive output in terms of circular economy and cleaner production to attain ethical business by achieving accuracy, precision, and efficiency also in the vehicle fleet [12]. Preventive maintenance in bus transport is an instrument for improvement. Proactive maintenance is a strategy to prevent malfunctions. Proactive maintenance has tasks that we divide into three categories: planned renewal, planned decommissioning, determining the conditions for monitoring the condition [13]. This strategy includes both preventive and predictive maintenance (Figure 1). Maintenance is one of the important processes of vehicle fleets. All processes affect the efficiency and functionality of the fleet vehicles, for bus transport purposes.

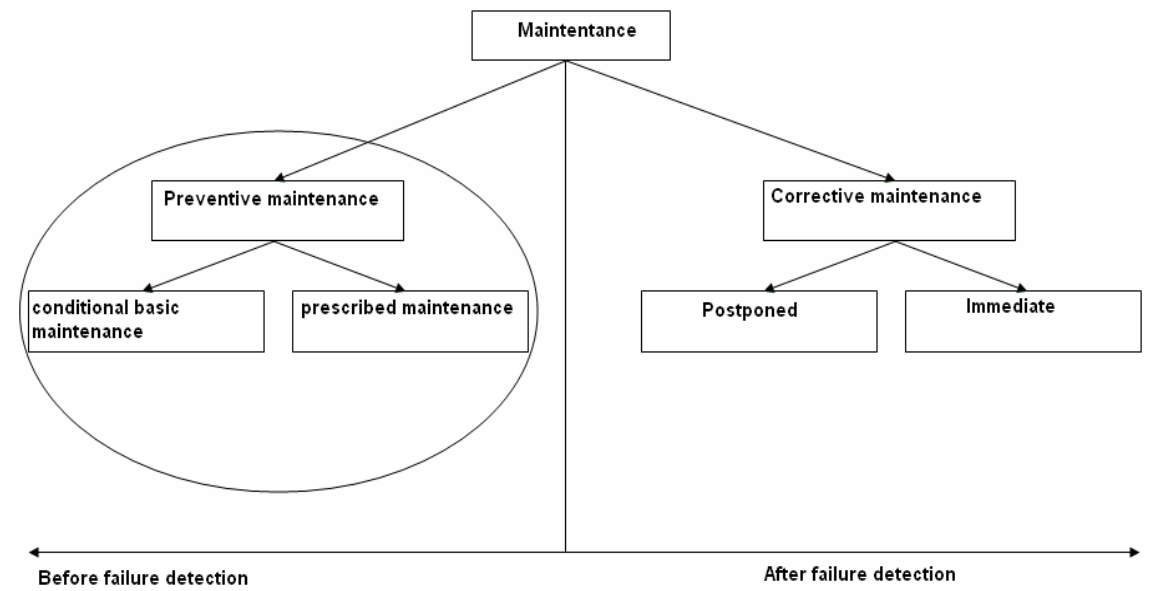

Figure 1

Maintenance according STN EN 13306 
The method of maintenance management is an important element of effective management of the entire organization. Maintenance is the process of managing technical and administrative activities throughout the life cycle of an object (Figure 2).

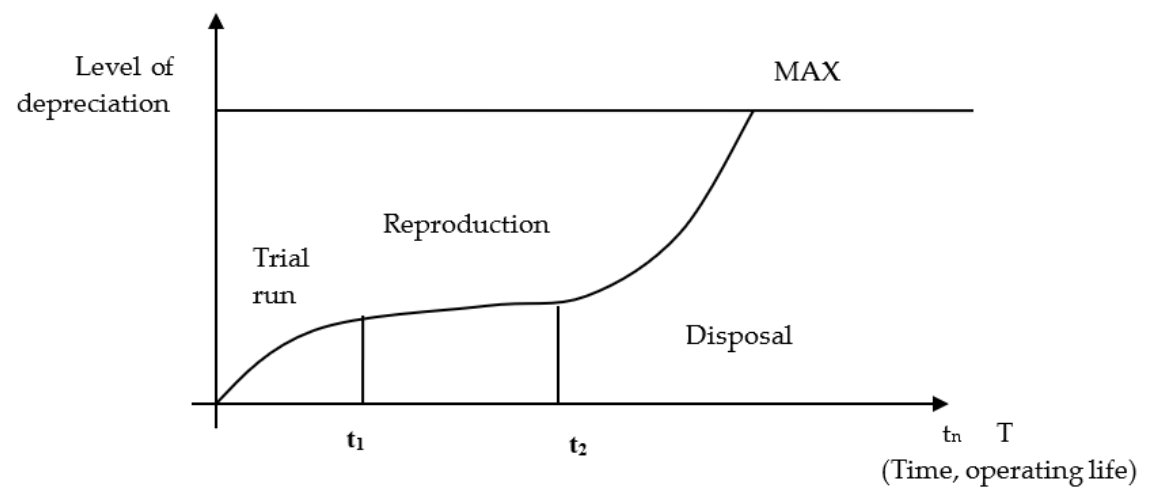

Figure 2

Economic life cycle of vehicle [13]

The aim of proactive maintenance is to maintain or restore its condition in which it can vehicle perform the required function, considering optimal costs and quality, safety, and environmental requirements. Maintenance is a set of activities that ensure the technical competence, readiness, and economic operation of the basic vehicle. It is a set of measures for securing and assessing the actual condition of machinery and equipment, as well as for maintaining and restoring their desired condition. The scope of maintenance activities is not specifically specified, this includes treatment (maintenance by cleaning and lubrication), inspection, repairs in case of equipment failures. Bashar et. al. commented that total productive maintenance (TPM), people management (HRM), and organizational performance are connected and influence the business profit of organizations [14]. The next possibility of bus transport is a hybrid system. Wang et al. [15] presented a hybrid system for sustainable cities that contains a combination of a bus system with a bike system. It means a low-carbon transport system because the bus system creates high $\mathrm{CO}_{2}$ emissions. The hybrid system reaches the most environmentally friendly state for big cities. The change of fuel to biodiesel can significantly reduce $\mathrm{CO}_{2}$ emission and energy consumption of the current bus system. The next problem in the bus transport area is periodic maintenance and long-term plan for daily parking, the assignment of bus blocks in the frame of compatibility. David et al. [16] have solved the problem with public transit, which aims to assign vehicle blocks of a planning period to buses in the fleet of a transportation company. They suggest a state-expanded multi-commodity flow network. This model takes bus parking constraints into account and assigns preventive maintenance. An important part of bus transport is bus stop and information at the bus stop for customers. Intelligent systems create opportunities for improvement in bus 
transport. These include smart meters, smart street lightings, smart gas stations, smart parking lots, and smart bus stops. Kamal et al. [17] said that the advent of smart sensors, single system-on-chip computing devices, the Internet of Things (IoT), and cloud computing is facilitating the design and development of smart devices and services in bus transport. They present major enhancements to the bus stops by installing air-conditioning units, but without any remote monitoring and control features. They present a smart IoT-based environmentally friendly enhanced design for existing bus stop services. Lauth et al. [18] present a methodology that addresses the challenges of designing a depot for electric vehicle fleets - bus. The wide variety of possible solutions are structured using a morphological matrix. A modular simulation and planning tool are introduced which takes technical and operational aspects into account. All these changes create an innovative approach in bus transport and services like maintenance, parking. In cities, public transportation service plays a vital role in the mobility of people. Introduction of a new route or increase in the frequency of buses, the nonrevenue kilometers covered by the buses increases as a depot and route starting/ending points are at different places. This problem is the next opportunity for improvement. Mahadikar et al. [19] said, that the reduction of dead kilometers is necessary for the economic growth of the public transportation system. They obtained information that minimizing dead kilometers depend on optimizing the allocation of buses to depots depending upon the shortest distance between the depot and route starting/ending points. On the base, this information began to solve the reduction of dead kilometers. Regular maintenance, which is performed according to a predetermined schedule, represents preventive maintenance. A special case of a preventive strategy is predictive maintenance and is focused on detecting warning signs of damage that has already begun [20]. Periodic resp. online condition monitoring and maintenance will be performed if the deterioration of the condition to a certain specified extent is detected [21]. In this case, however, maintenance will only work on parts whose condition has been recorded as deteriorated. This prevents the fault, but usually does not eliminate the primary cause of the deterioration.

\section{Material and Methods}

As part of the research, we proceeded based on the algorithm of steps (Figure 3), which was the basic tool for managing the implemented project. Various methods were used in solving the project, such as analytical, simulation, experimental, graphical. We deal with the economic life cycle of vehicles in the phase of reproduction and the phase of disposal. The economic life-cycle of vehicles in the phase of reproduction means the modernization of vehicles, repair of vehicles, or buying new vehicles with the same characteristics. 


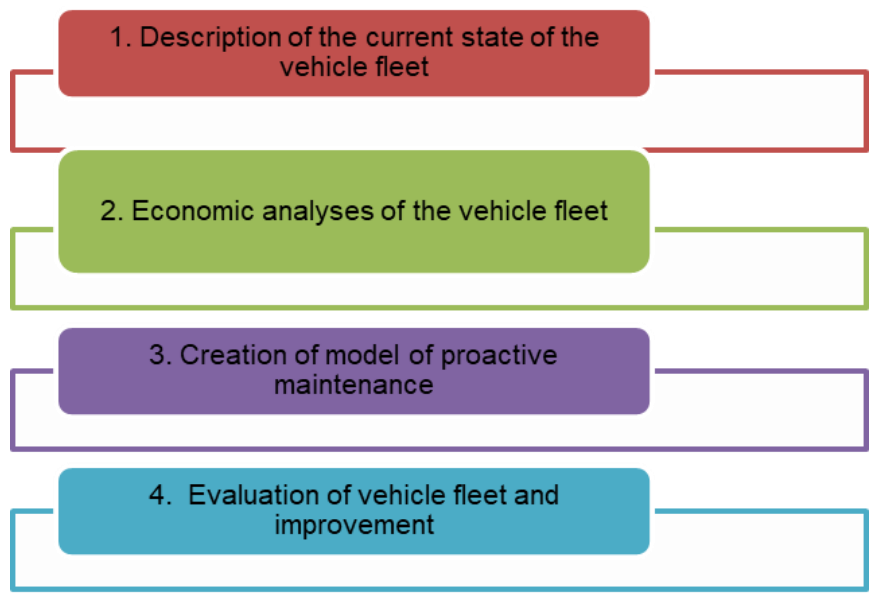

Figure 3

Algorithm of research

In the area of economic analysis, we used Pareto analysis. In the field of quality management, it is one of the most effective, commonly available and easy-toapply tools. It states that $20 \%$ of the causes, are causally related, to $80 \%$ outcomes of poor quality. It makes it possible to separate the essential factors of a certain problem from the less significant ones and to show which direction to focus on efforts to eliminate shortcomings in the quality assurance process. We rank the causes from the largest to the smallest value. Let us create a bar graph.

We determine the percentage of causes based on the formula Structure $(S)$ :

$$
S(\%) \frac{X i}{S U M X i} * 100(\%)
$$

Then we determine the Lorenz curve using cumulative percentages and plot a line graph. According to the Lorenz curve, we determine the maintenance services that are critical and that need to be addressed in the transport company, because they represent high costs for buses maintenance.

\subsection{Description of the Current State of the Vehicle Fleet}

To carry out the research of the vehicle fleet, it was necessary to prepare a description of the current state of the vehicle fleet-buses. The research was focused on the fleet of buses operated by the transport company. The aim of the research was to determine the condition of the vehicle fleet and the efficiency of the bus maintenance process, due to the technical and economic problems of the transport company. The first prototype of the SOR NB 12 (Figure 4) bus was 
manufactured in 2006 by the Czech manufacturer SOR Libchava. It was put into operation in 2012.

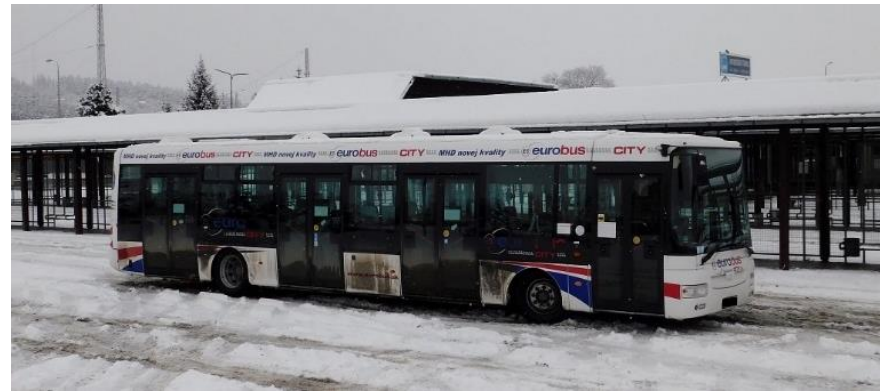

Figure 4

Vehicles SOR NB 12

Iveco Crossway LE 12M (Figure 5) was manufactured in 2008. The buses were manufactured at the Irisbus Iveco plant in Vysoké Mýto in Czech Republic.

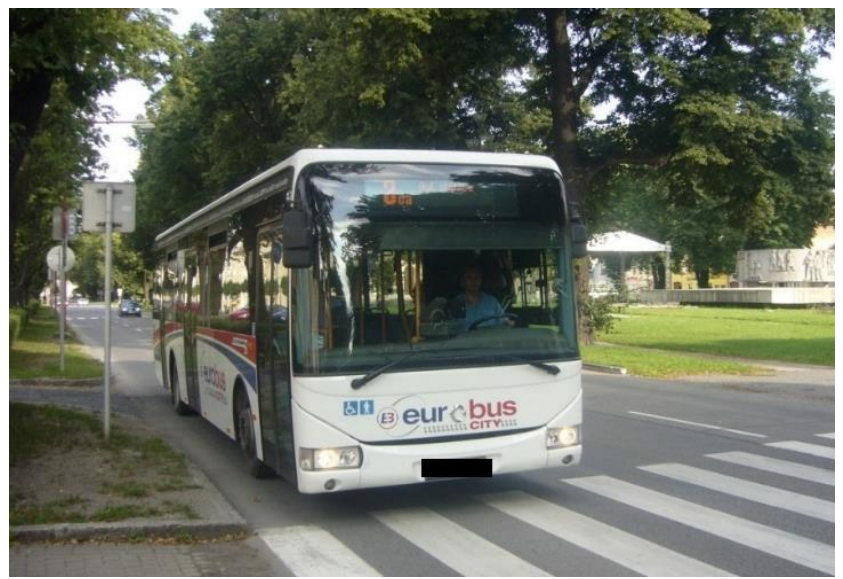

Figure 5

Vehicle Iveco Crossway LE 12M

Iveco First FCLLI buses (Figure 6) were manufactured in Slovakia in the company Rošero - P in the year 2008. The reason for purchasing this bus was the need to provide transport, more economically, on connections that are unprofitable for classic buses. They started in operation in 2009. 


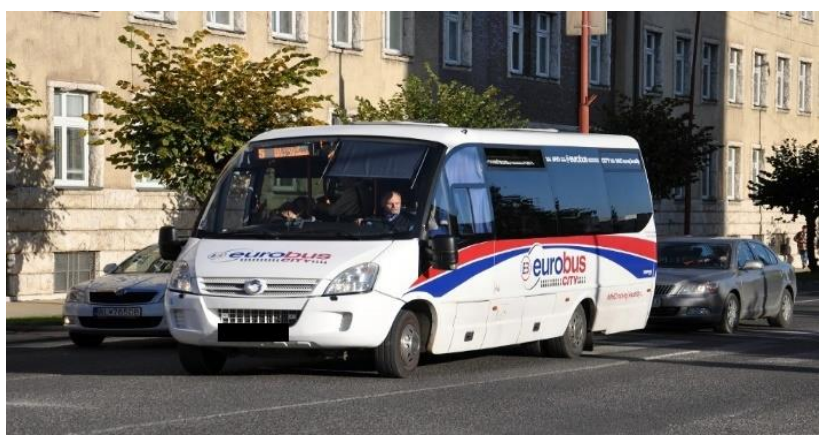

Figure 6

Vehicle Iveco First FCLLI

\section{Results}

In the research analytical portion, we focused on the economic analysis of the maintenance process in the bus fleet. In the first step, we monitored the activities in the maintenance process according to category M1 for selected buses. As part of the fleet research, we performed an analysis of service activities (Table 1) in the category: Service standard. The basic criteria for the service standard category are the distance traveled $40,000 \mathrm{~km}$, complete bus service once a year, or the number of bus hours 800 hours. Some service activities are not necessary for the specified category M1.

Table 1

Analysis of service activities

\begin{tabular}{|c|c|c|c|}
\hline Type of service activities M1 & SOR NB12 & $\begin{array}{l}\text { IVECO } \\
\text { CROSSWAY } \\
\text { LE12M } \\
\end{array}$ & \begin{tabular}{|l|} 
IVECO \\
FIRST \\
FCLLI \\
\end{tabular} \\
\hline Engine oil change & $\bullet$ & $\cdot$ & $\cdot$ \\
\hline Engine oil filter replacement & • & • & • \\
\hline Fuel pre-filter cartridge replacement & & & $\cdot$ \\
\hline Engine blow by filter replacement & $\cdot$ & $\cdot$ & \\
\hline Replacement of the antifouling filter & - & • & \\
\hline $\begin{array}{l}\text { Checking the fluid level in the hydraulic } \\
\text { system }\end{array}$ & $\cdot$ & $\cdot$ & $\cdot$ \\
\hline Total chassis lubrication & - & • & \\
\hline Checking the condition of various belts & $\cdot$ & $\bullet$ & • \\
\hline External radiator wash & $\cdot$ & $\cdot$ & \\
\hline Checking the effectiveness of the axle vent & & & $\bullet$ \\
\hline
\end{tabular}




\begin{tabular}{|l|c|c|c|}
\hline Type of service activities M1 & SOR NB12 & $\begin{array}{l}\text { IVECO } \\
\text { CROSSWAY } \\
\text { LE12M }\end{array}$ & $\begin{array}{l}\text { IVECO } \\
\text { FIRST } \\
\text { FCLLI }\end{array}$ \\
\hline Inspection of tie rods, joints, and steering shaft & & & $\cdot$ \\
\hline $\begin{array}{l}\text { Check the tightness of the hydraulic brake } \\
\text { lines and the cooling system }\end{array}$ & $\bullet$ & $\bullet$ & $\bullet$ \\
\hline $\begin{array}{l}\text { Check the wear rate of the brake discs and } \\
\text { brake pads }\end{array}$ & $\cdot$ & $\cdot$ & $\bullet$ \\
\hline Check the engine EDC system with E.A.SY & & & $\bullet$ \\
\hline Ad blue device test using E.A.SY function & $\bullet$ & $\bullet$ & \\
\hline Check on the road & $\bullet$ & $\bullet$ & $\bullet$ \\
\hline
\end{tabular}

Based on detailed economic analyzes for the service activities of the bus fleet, we found the activities that are financially the most expensive for the transport company (Table 2). These activities include in particular: Planning service, Belts, Replacement engine oil, Testing of failure, Oil filter, Radiator wash, Brake lines, Cooler, Shock absorbers. In addition to these critical activities and spare parts, other important activities are performed in the bus maintenance system, and various spare parts are needed. However, they are not that expensive and do not pose a significant problem within the fleet maintenance system. Given that the bus fleet maintenance system presents both economic and technical problems, it is necessary to analyze critical service activities.

Table 2

Type of critical service activities

\begin{tabular}{|l|c|c|c|}
\hline $\begin{array}{l}\text { Type of service activities, } \\
\text { replacement parts (€) }\end{array}$ & SOR NB12 & $\begin{array}{l}\text { IVECO } \\
\text { CROSSWAY } \\
\text { LE12M }\end{array}$ & $\begin{array}{l}\text { IVECO } \\
\text { FIRST } \\
\text { FCLLI }\end{array}$ \\
\hline Planning service & 1800 & 850 & 180 \\
\hline Belts & 1400 & 560 & 60 \\
\hline Replacement engine oil & 1200 & 1100 & 80 \\
\hline Testing of failure & 800 & 300 & 95 \\
\hline Oil filter & 750 & 600 & 35 \\
\hline Radiator wash & 500 & 200 & 25 \\
\hline Brake lines & 350 & 750 & 110 \\
\hline Cooler & 2100 & 4500 & 350 \\
\hline Shock absorbers & 2860 & 3000 & 460 \\
\hline
\end{tabular}

\subsection{Economic Analyses of the Vehicle Fleet}

Based on the performed Pareto analysis according to formula (1), we found critical service services that are very costly for individual types of buses. 
The type of bus SOR NB12 (Figure 7), based on Pareto analysis, presents critical service activities as an $20 / 80 \%$ split, the critical services are shock absorbers, cooler, planning service, belts and the replacement of engine oil. The critical activity limit is determined based on a point on the Lorenz curve of $80 \%$ and are perpendicular to the $\mathrm{x}$-axis. The economic aspect is the movement of costs at the level from $1200 €$ to $2860 €$. Those activities or spare parts are the critical category $20 \%$ of maintenance activities and $80 \%$ costs of maintenance.

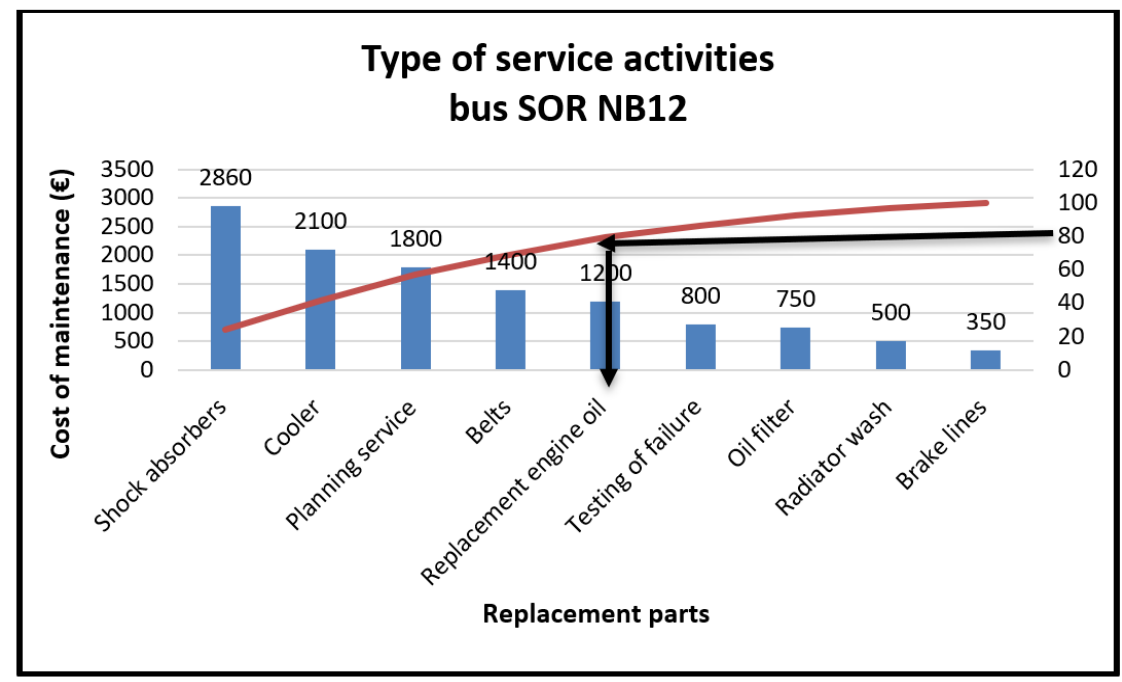

Figure 7

Pareto analysis SOR NB12

The type of bus IVECO CROSSWAY LE12M (Figure 8) based on Pareto analysis presents critical service activities on the principle (20/80\%). They are cooler, shock absorbers, replacement engine oil, planning service. The critical activity limit is determined based on a point on the Lorenz curve of $80 \%$ and a perpendicular to the $\mathrm{x}$-axis. The economic aspect is the movement of costs at the level from $850 €$ to $4500 €$. Those activities or spare parts are the critical category $20 \%$ of maintenance activities and $80 \%$ costs of maintenance. 


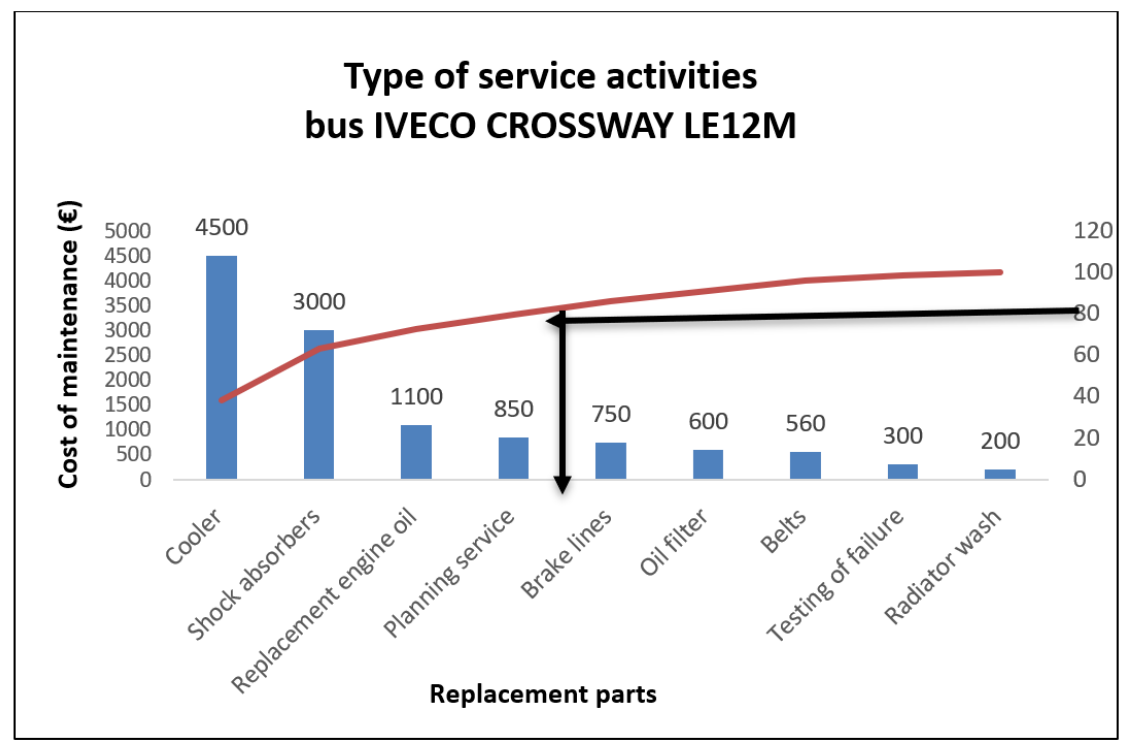

Figure 8

Pareto analysis IVECO CROSSWAY LE12M

The type of bus IVECO FIRST FCLLI (Figure 9) based on Pareto analysis presents critical service activities on the principle (20/80\%). They are shock absorbers, cooler, planning service, brake lines. The critical activity limit is determined based on a point on the Lorenz curve of $80 \%$ and a perpendicular to the $\mathrm{x}$-axis.

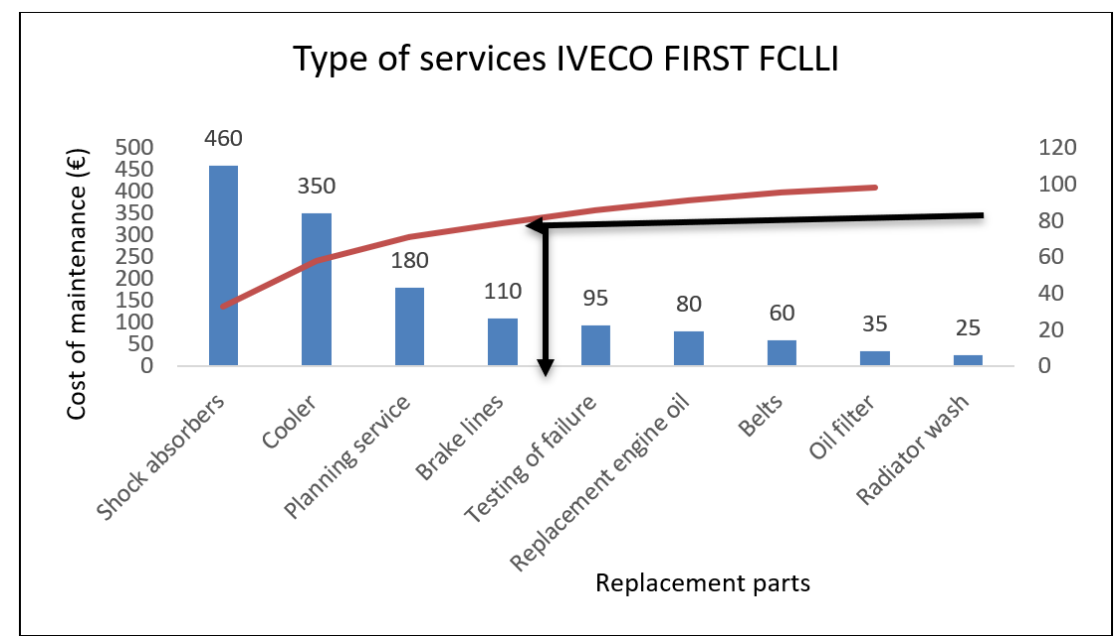

Figure 9

Pareto analysis IVECO FIRST FCLLI 
The economic aspect is the movement of costs at the level from $110 €$ to $460 €$. Those activities or spare parts are the critical category $20 \%$ of maintenance activities and $80 \%$ costs of maintenance. $20 \%$ of maintenance activities account for $80 \%$ of maintenance costs and therefore it is necessary to pay attention to these activities in the maintenance process.

\subsection{Creation of Model of Proactive Maintenance}

Critical maintenance activities as cooler, shock absorbers, replacement engine oil, planning service, brake lines, belts need to be planned as part of preventive maintenance. It is important to plan for these critical activities in the maintenance process for the bus fleet as part of proactive maintenance (Figure 10) to minimize the cost of spare parts and critical activities in the maintenance process.

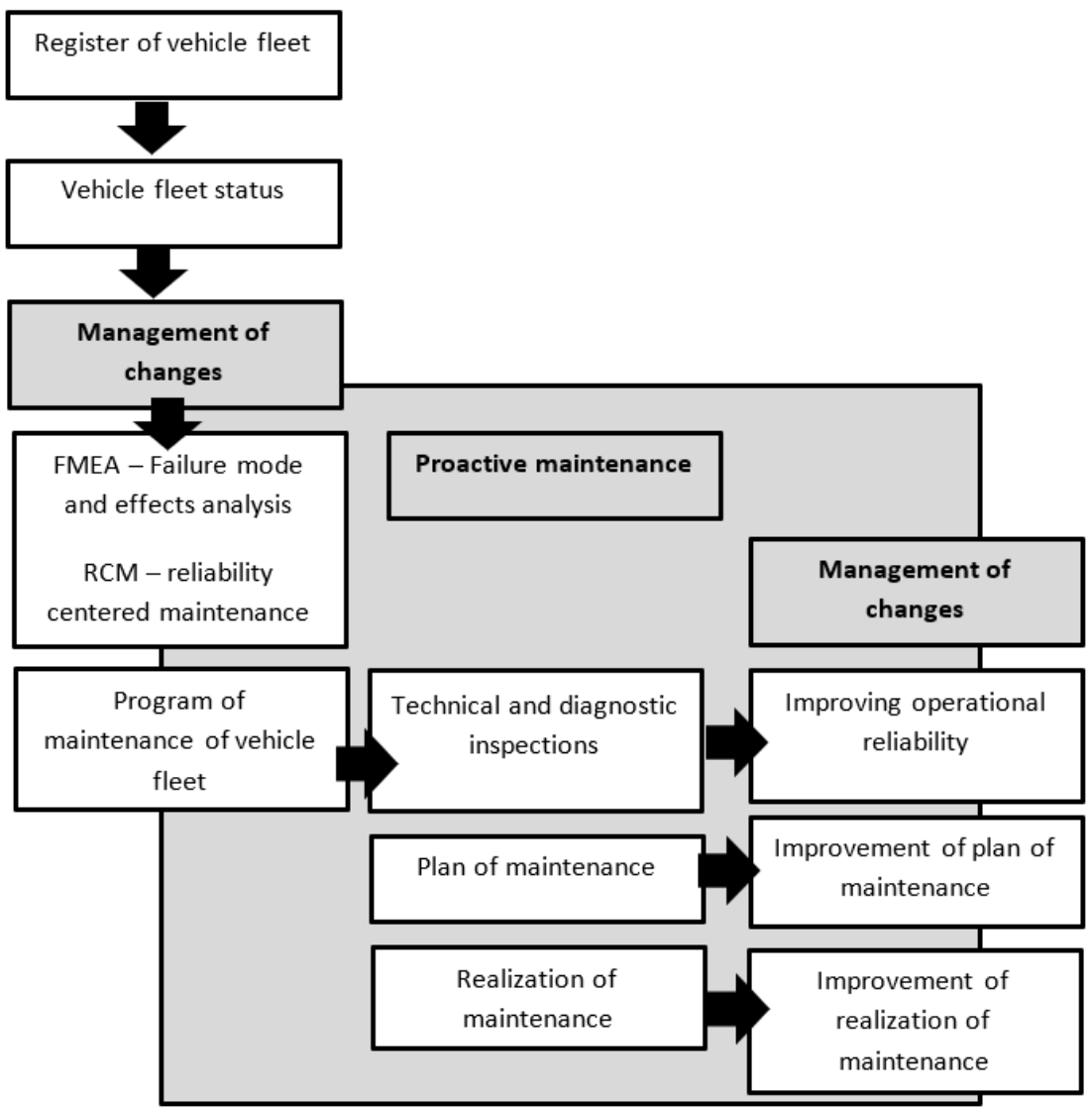

Figure 10

Proactive model of maintenance management 
Proactive maintenance requires the planning of activities that prevent bus breakdowns. In this way, they minimize activities related to repairing faults, replacing spare parts, and performing regular preventive service activities. The proactive maintenance model is based on the use of change management approaches in terms of technical and diagnostic control of vehicles - buses, maintenance planning focused on preventive maintenance, implementation of maintenance activities with a focus on cost minimization.

\subsection{Evaluation of Vehicle Fleet and Improvement}

Based on the above approach, it is possible to achieve changes in the maintenance process and create an effective maintenance system in the transport company's bus fleet. High bus maintenance costs, lack of spare parts, lack of functional buses are problems for the vehicle fleet. Focusing on the new three approaches according to the proactive maintenance model will bring the transport company improved maintenance planning, improvements in the implementation of maintenance activities, improved operational reliability of vehicles-buses, which ultimately means satisfying customer requirements.

\section{Discussion}

Proactive maintenance is orientated on new innovative approaches in maintenance (TPM, RCM). According to the level of generations of maintenance, all the firms can decide, what form of maintenance use from the view of care for vehicles (Figure 11). The tendency of maintenance depends on the character of the firm. The third generation of maintenance level is orientated on reliability, security, quality, costs, environment, and durability of the vehicle. This approach is preferred around maintenance management circles today.

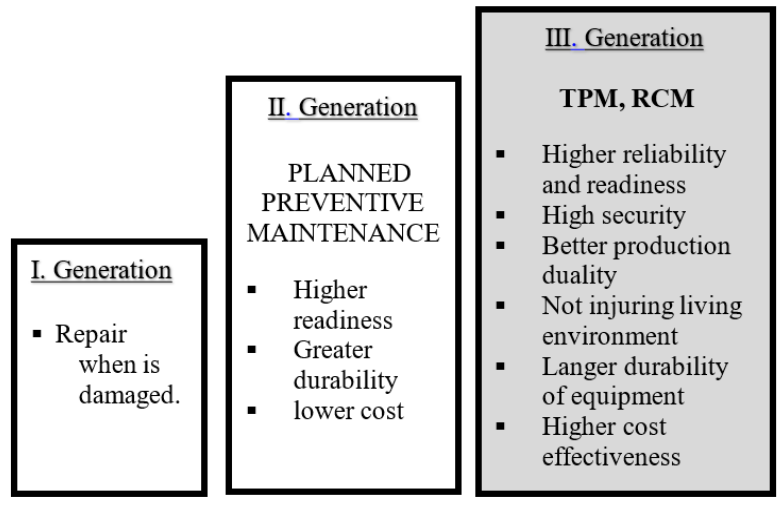

Figure 11

Generation of maintenance management 
Rajput et. al [12] said Industry 4.0 offers a productive output in terms of circular economy and efficiency. This approach is used in transport companies so, that bring implementation proactive maintenance in vehicle fleet for buses. This proactive maintenance brings economic benefit in reduction of costs and technical benefit for the realization of maintenance activities and buying new spare parts for vehicle fleet buses. Bashar et al. [14] commented that total productive maintenance (TPM), people management (HRM), and organizational performance are connected and influence the business profit of organizations. This connection brought for the vehicle fleet important significance because the transport company implemented proactive maintenance, the employees of maintenance absolved training, the performance of the transport company was improved, and maintenance reduced all cost for three buses of the vehicle fleet. Wang et al. [15] presented a hybrid system for sustainable cities that contains a combination of a bus system with a bike system. This transport company offer service for cities in bus system only. Transport company does not competencies for implementation hybrid system, because it is opportunities for the public sector. It is possible to create a hybrid system with a bus system, bike system, train transport.

\section{Conclusion}

Maintenance is one of the most important processes that affect productivity and creates added value, for the main process, within every company. Proactive maintenance is a key instrument for the operation of vehicle fleets of bus transport and its significance is in terms of economic, technical, social and environmental benefits. High costs and high energy consumption are factors for changes in the vehicle fleet of bus transport areas. The aim of this work was to describe the process of vehicle fleet maintenance and provide an evaluation of economic and technical benefits, in terms of the optimization of the entire maintenance process. We used economic, comparative analysis to evaluate the maintenance process and the Pareto analysis, based on the $80 / 20 \%$ principle. The results provide critical service activities for each type of bus. Critical services of the maintenance process are shock absorbers, cooler, planning service, brake lines. Paramount, in the maintenance process, is cost optimization, capacity planning, workload utilization, optimal material delivery and monitoring the fulfillment of the plan in each company and in various areas of industry. The Industry 4.0 concept, or in integrating the smart system in transport, is also, an important step in the sustainability of bus transport.

\section{Acknowledgement}

The article was prepared with the support from the project VEGA 1/0429/18 and VEGA 1/0317/19.

\section{References}

[1] Laloix, T., Voisin, A., Deeb, S., Romagn, E., Iung, B., Lorange, F.: Industrial system functioning/dysfunctioning-based approach for indicator 
identification to support proactive maintenance, IFAC PapersOnLine 50-1, 2017, pp. 13704-13709

[2] Exner, K., Schnürmacher, C., Adolphy, S., Stark, R.: Proactive maintenance as success factor for use-oriented Product-Service Systems, Procedia CIRP 64, The $9^{\text {th }}$ CIRP IPSS Conference: Circular Perspectives on Product/Service-Systems, 2017, pp. 330-335

[3] Zhou, B., Qi, Y., Liu, Y.: Proactive preventive maintenance policy for buffered serial production systems based on energy saving opportunistic windows, Journal of Cleaner Production, 253, 2020, pp. 1-14

[4] Yang, L., Zhao, Y., Peng, R., Ma, X.: Hybrid preventive maintenance of competing failures under random environment, Reliability Engineering \& System Safety, 174, 2018, pp. 130-140

[5] Škerlič, S., Sokolovskij, E., Erčulj, V.: Maintenance of heavy trucks: an international study on truck drivers, Eksploatacja i Niezawodnosc Maintenance and Reliability, 22 (3), 2020, pp. 493-500

[6] Zhou, Y., Kou, G., Xiao, H., Peng, Y., Alsaadi, F. E.: Sequential imperfect preventive maintenance model with failure intensity reduction with an application to urban buses, Reliability Engineering and System Safety, 198, 2020, pp. 1-11

[7] Zhou, R., Fox, B., Lee, H. P., Nee, A. Y. C.: Bus maintenance scheduling using multi-agent systems, Engineering Applications of Artificial Intelligence, 17, 2004, pp. 623-630

[8] Haghani, A., Shafahi, Y.: Bus maintenance systems and maintenance scheduling: model formulations and solutions, Transportation Research Part A, 36, 2002, pp. 453-482

[9] Niewczas, A., Rymarz, J., Debicka, E.: Stages of operating vehicles with respect to operational efficiency using city buses as an example, Eksploatacja i Niezawodnosc - Maintenance and Reliability, 21 (1), 2019, pp. 21-27

[10] Ambriško, L.: Analysis of public transport vehicles maintenance costs, CLC 2018 Carpathian Logistics Congress, Ostrava, 2019, pp. 368-373

[11] Horváth, C., Gaál, Z.: Operating maintenance model for modern printing machines, Acta Polytechnica Hungarica, 5 (3), 2008, pp. 39-47

[12] Rajput, S., Singh, S. P.: Indurstry 4.0 model for circular economy and cleaner production, Journal of Cleaner Production, 277, 2020, 123853

[13] Teplická, K., Straka, M.: Sustainability of extraction of raw material by a combination of mobile and stationary mining machines and optimization of machine life cycle, Sustainability, 12 (24), 2020, pp. 1-13 
[14] Bashar, A., Hasin, A. A., Jahangir, N.: Linkage between TPM, people management and organizational performance, Journal of Quality in Maintenance Engineering, 2020, 10.1108/JQME-11-2019-0105

[15] Wang, S. S., Wand, H., Xie, P. Y., Chen, X. D.: Life-cycle assessment of carbon footprint of bike-share and bus systems in capus transit, Sustainability, 13 (1), 2021, 1-14

[16] David, B., Kresz, M.: Multi-depot bus schedule assignement with parking and maitenance constraints for intercity transportation over a planning period, Transportation Letters - the International Journal of Transportation Research, 12 (1), 2020, pp. 66-75

[17] Kamal, M., Atif, M., Jujahid, H., Shanableh, T., Al-Ali, A. R., Al Nabulsi, A.: IoT based smart city bus stops, Future Internet, 11 (11), 2019, 1-11

[18] Lauth, E., Mundt, P., Gohlich, D.: Simulation based planning of depots for electric bus fleets considering operations and charging management, The $4^{\text {th }}$ International Conference on Intelligent Transportation Engineering, 2019, pp. 327-333

[19] Mahadikar, J., Mulangj, R. H., Sitharam, T. G.: Optimization of bus allocation to depots by minimizing dead kilometers, Journal of Advanced Transportation, 49 (8), 2015, pp. 901-912

[20] Ambriško, L', Marasová, D., Cehlár, M.: Investigating the tension load of rubber composites by impact dynamic testing, Bulletin of Materials Science, 40 (2), 2017, pp. 281-287

[21] Ambriško, L. Et al.: Mechanical properties and chemical composition of rubber gaskets, Przemysł Chemiczny - Chemical Industry, 99 (4), 2020, pp. 598-601 